\title{
The Effects of Vit E and Vit C Use on Ovarian Surface Epithelium and Follicle Reserve in Autologous Intraperitoneal Ovarian Transplantation in Rats: An Experimental Study
}

\author{
Tansel Sapmaz ( $\nabla$ sapmaz.tansel@gmail.com ) \\ University of Health Sciences, Istanbul, Turkey \\ Ebru Kale \\ University of Health Sciences, Istanbul, Turkey \\ Halime Hanim Pence \\ University of Health Sciences, Istanbul, Turkey \\ Kubra Sevgin \\ University of Health Sciences, Istanbul, Turkey \\ Muhammetnur Tekayev \\ University of Health Sciences, Istanbul, Turkey \\ Sude Topkaraoglu \\ University of Health Sciences, Istanbul, Turkey \\ Gulfem Basol \\ University of Health Sciences, Istanbul, Turkey \\ Muserref Banu Yilmaz \\ University of Health Sciences, Istanbul, Turkey \\ Ekrem Sapmaz \\ University of Health Sciences, Istanbul, Turkey \\ Oktay Irkorucu \\ University of Sharjah
}

\section{Research Article}

Keywords: Ovary, Follicle, Transplantation, Vit C, Vit E.

Posted Date: November 23rd, 2021

DOI: https://doi.org/10.21203/rs.3.rs-1088363/v1

License: (a) This work is licensed under a Creative Commons Attribution 4.0 International License. Read Full License 
Page 2/14 


\section{Abstract}

Purpose: The aim of this study was to investigate the effects of vitamin E (Vit E) and vitamin C (Vit C) on oxidant-antioxidant system markers, ovarian follicle reserves, and surface epithelium in autologous intraperitoneal ovarian transplantation in rats.

Materials and Methods: 20 adult female Wistar Albino were randomly divided into four groups. Group 1 (n $=5)$, the control group, only had their abdomens opened and closed. Group $2(n=5)$ : underwent an ovarian transplantation. Group $3(n=5)$ received $20 \mathrm{mg} / \mathrm{kg}$ of intraperitoneal (IP) Vit E 15 minutes before an ovarian transplantation. Group $4(n=5)$ received $50 \mathrm{mg} / \mathrm{kg}$ of IP Vit $C$ that was administered 15 minutes before an ovarian transplantation.

Vaginal cytology was performed to monitor the oestrus phase. Biochemically, tissue and serum malondialdehyde levels and erythrocyte superoxide dismutase (SOD) levels were measured. Histopathologically, the number dysplastic changes in the ovarian surface epithelium were examined.

Results: Dysplastic changes in the surface epithelium of Group 2 were found to be significantly higher than in Group 1 and $4(p<0.02)$. In Group 2, the ovarian follicle reserves were significantly lower than in other groups $(p<0.02)$. In addition, a significant decrease in SOD levels was found in Group 2 compared to other groups $(p<0.02)$.

Conclusion: The study showed that Vit $\mathrm{E}$ and Vit $\mathrm{C}$ in autologous intraperitoneal ovarian transplantation preserved the ovarian follicle reserve. Vit $\mathrm{C}$ was found to be more effective than Vit $\mathrm{E}$.

\section{Introduction}

Although ageing and gonadotoxic treatments for cancer and some autoimmune diseases are the leading causes of infertility, bilateral oophorectomy is another cause of fertility loss in women. Aggressive surgery, chemotherapy, and radiotherapy administered to women diagnosed with cancer in reproductive age cause irreversible damage to ovarian follicles and oocytes, premature ovarian failure, and fertility loss (1-4). However, advances in medicine have led to the increased survival rates for patients today and made the loss of fertility a significant issue. This has led to a change in the mentality of doctors, who know think both about curing the patient through treatment and about ovary preservation for the future. Ovarian transplantation may be a good option for such patients. However, after ovarian transplantation, follicular losses can occur due to reoxygenation and ischaemic injury caused by a poor vascular bed. Therefore, controlling ischaemia is crucial to increase surviving follicles during and following transplantation $(5,6)$.

Vitamin $\mathrm{E}$ (Vit E) is a fat-soluble antioxidant that protects cell membranes from reactive oxygen species. It acts as a radical scavenger, giving hydrogen $(H)$ atoms to free radicals. Due to its fat-solubility, Vit $E$ is incorporated into cell membranes to protect them from oxidative damage. Vit $\mathrm{E}$ has the potential to 
protect the ovarian epithelium from oxidative DNA damage and metaplasia that is caused by ovulation (7).

Vitamin C (Vit C) is a hydrophilic vitamin with an antioxidative effect. It plays a role in tissue repair and in the enzymatic production of some neurotransmitters. It is necessary for enzyme activity and has essential functions in the immune system. It also acts as an antioxidant. It has immunomodulatory activity and also provides genomic stability by reducing DNA damage (8). Vit C plays an essential role in limiting lipid peroxidation and scavenges reactive oxidants produced after reperfusion (9).

There are no studies that demonstrate the effect of Vit $E$ and Vit $C$ on antioxidant system markers and on the ovarian surface epithelium of ovaries in auto-transplanted rats who have received whole ovarian transplantation.

The aim of the study was to investigate the effects of Vit $E$ and Vit $C$ on oxidant-antioxidant system markers and on the ovarian surface epithelia and follicle reserves in rats who had received autologous intraperitoneal ovarian transplants.

\section{Materials And Methods}

The experimental study was conducted in the laboratory of the University of Health Sciences, Faculty of Medicine. Ethical approval of the project (No. 46418926-605.02 May 2018) was obtained from the Health Sciences University Hamidiye Animal Experiments Local Ethics Committee (Istanbul, Turkey). All surgical procedures and maintenance protocols used were planned and carried out by following the guidelines set out in the 'Care and Use Manual of Laboratory Animals'.

20 adult female Wistar Albino rats that were 12-weeks old and weighed $250-300 \mathrm{~g}$ were used. The rats were fed with standard pellet feed and city water and were kept in a room with a 12-hour light (08:00 22: 00 ) and a 12 -hour dark photoperiod, at a constant temperature of $21^{\circ} \mathrm{C}-23^{\circ} \mathrm{C}$. The rat's oestrus phases were determined by vaginal cytology follow-up. Vaginal cytology was perfumed using the Papanicolaou stain and evaluated with an ordinal scale (cells cannot be evaluated $=0$ points, atrophic $=$ 1 point, hypertrophic $=2$ points, trophic $=3$ points $)$.

The rats were randomly divided into four groups.

Group $1(\mathrm{G} 1, \mathrm{n}=5)$ : Control group. The abdomen was opened and closed.

Group $2(G 2, n=5)$ : Model group. Underwent a left unilateral oophorectomy and ovarian transplantation after 15 minutes.

Group $3(\mathrm{G} 3, \mathrm{n}=5)$ : Vit E group. Received $20 \mathrm{mg} / \mathrm{kg} /$ intraperitoneal (IP) Vit E (100mg Evicap amp®, Kocak Farma, Tekirdag, Turkey) administered 15 minutes before left unilateral oophorectomy and ovarian transplantation. 
Group 4 (G4, n = 5): Vit C group. Received 20 mg/kg/IP Vit C (Redox amp® C, Bayer, Turkey) administered 15 minutes before left unilateral oophorectomy and ovarian transplantation.

Ovarian transplantation was performed under anaesthesia ( $75 \mathrm{mg} / \mathrm{kg}$ ketamine and $10 \mathrm{mg} / \mathrm{kg}$ xylazine). Transplantation of the ovaries was performed 15 minutes after the administration of the antioxidants in G3 and G4.

\section{Ovarian Transplantation}

The rats were placed in the supine position on the operating table, and the abdomen was opened through a midline incision. The rats' blood pressure, heart rate, and temperature were monitored and measured during the study. Left unilateral oophorectomy was performed 15 minutes after the administration of antioxidant drugs. First, the ovaries were cleared of adipose tissue, divided into two equal parts, and sutured to the vascular plexus of the peritoneal wall with 3/0 vicryl (Ethicon, Edinburgh, UK). Next, the abdominal layers and skin were sutured with $3 / 0$ silk.

Rats were kept in separate cages until the end of the experiment (10 days). On the 10th postoperative day, all rats were euthanised via decapitation under anaesthesia/sedative (ketamine $75 \mathrm{mg} / \mathrm{kg}$ and xylazine $10 \mathrm{mg} / \mathrm{kg}$ ). Blood samples were collected intracardially prior to decapitation. The left ovary of $\mathrm{G} 1$ and the transplanted left ovaries of G2, G3, and G4 were removed. For laboratory parameters, ovarian tissue and serum MDA were indicators of oxidative damage, while erythrocyte superoxide dismutase (SOD) activity was used as an antioxidant marker. Preparations were stained with Hematoxylin \& Eosin (H\&E) for histopathological examination.

\section{Tissue/Serum MDA and Erythrocyte SOD Examination}

Half of the ovarian tissue from each rat was stored at $-80^{\circ} \mathrm{C}$ for tissue MDA analysis. $150 \mathrm{mg}$ of the remaining tissue was used to evaluate the tissue MDA level. Tissue MDA level was determined as $\mathrm{nmol} / \mathrm{g}$ tissue as outlined in the method used by Ohkawa et al. (10).

Serum MDA was analysed in $5 \mathrm{ml}$ blood samples that were taken from the lower vena cava of the rats. First, serum MDA level was measured by the Satoh and Yagi method as $\mathrm{nmol} / \mathrm{ml}(11,12)$. Then, the $5 \mathrm{ml}$ blood samples were placed in EDTA tubes, and erythrocyte SOD levels were examined. The erythrocyte SOD level was measured using the RANSOD kit (Randox, Crumlin, UK), and the haemoglobin level was measured as $\mathrm{U} / \mathrm{g} \mathrm{Hb}$ using the Drabkin method (13).

\section{Histopathological Evaluation}

The remaining tissue was fixed in $10 \%$ formaldehyde solution and embedded in paraffin blocks for histological examination. The paraffin-embedded tissue samples were then stained with H\&E to identify follicle reserves and dysplastic changes on the ovarian surface epithelium. Three sections of ovarian tissue were selected, corresponding to approximately $25 \%, 50 \%$ and $75 \%$ of the tissue block. Two blind observers evaluated the same sections independently, and the results obtained were compared and found 
to be $90 \%$ congruent. Primordial, primary, secondary, and tertiary follicles were counted in the samples via examination under light microscopy, as proposed by Souza et al. (14). Ovarian follicle reserves were determined through the collection of all the follicles (14).

Stratification, tufting, chromatin irregularity, nuclear contour irregularity, increase in the nuclearcytoplasmic ratio, pleomorphism, nucleoli of epithelial cell presence, mitosis, and hyperchromasia are all indicators of dysplastic changes in the epithelium of ovarian tissue. Each indicator was evaluated in the tissue preparations according to the ordinal scale created by Sapmaz et al. $(0=$ none, $1=$ mild, $2=$ moderate, 3 = high) (15). The ovarian surface epithelial dysplastic change score was calculated by summing the values of all parameters in each preparation.

\section{Statistical Analysis}

The SPSS 15.0 program was used for statistical analysis. The Kruskal-Wallis variance analysis was used to compare the continuous variables among four groups. For parameters found to be significant $(\mathrm{p}<$ 0.05), the MWU test with Bonferroni correction was used for binary comparisons, where $p<0.02$ was considered significant in order to prevent significance inflation.

\section{Results}

The experiment was successful in all rats. Age (week) and weight $(\mathrm{g})$ of all rats were similar $(\mathrm{p}>0.05)$. In addition, it was macroscopically observed in multiple rats that the ovarian tissue adhered to the peritoneal wall. Furthermore, neovascularisation occurred in the tissue after transplantation in all experimental groups (G2, G3, G4; Figure 1).

In the histopathological findings, changes in the ovarian surface epithelia were determined by examining stratification, tufting, chromatin irregularity, nuclear contour irregularity, increase in the nuclearcytoplasmic ratio, pleomorphism, nucleolus presence of epithelial cells, mitosis, and hyperchromasia in H\&E-stained preparations for each group. All parameters of the changes in the ovarian surface epithelium for each group are shown in Table 1. In G2, dysplastic changes in the surface epithelium were significantly higher compared to in $\mathrm{G} 1$ and $\mathrm{G} 4$ ( $p<0.02$, MWU test). Although dysplastic changes were decreased in G3, they were not significantly decreased compared to $G 2$ ( $p>0.02$, MWU test). Although the chromatin irregularity, nucleolus presence of epithelial cells, and mitosis values were similar in G2 compared to the other groups ( $p>0.02, \mathrm{MWU}$ test), all other parameters were found to be significantly increased in $\mathrm{G} 2$ ( $p<0.02$, MWU test). The harmful effects seen in $\mathrm{G} 2$ decreases with the use of Vit $E$ and Vit $C$ in $G 3$ and $G 4$. In G4, a significant reduction in dysplastic changes was observed $(p<0.02$, MWU test). The increased stratification, tufting, hyperchromasia, and pleomorphism in $\mathrm{G} 2$ are shown in Figure 2. The marked decrease in dysplastic changes of the ovarian surface epithelium of $\mathrm{G} 4$ can be seen in Figure 2D.

Ovarian surface epithelial changes, follicle reserves, tissue MDA, serum MDA, and erythrocyte SOD levels in all groups are shown in Table 2. Serum and tissue MDA levels were significantly increased in G2 
compared to the other groups ( $p<0.02$, MWU test). In addition, a significant decrease in erythrocyte SOD levels was seen in $\mathrm{G} 2(\mathrm{p}<0.02$, MWU test). Additionally, a striking increase in nuclear hyperchromasia and superficial epithelial cell enlargement due to high-grade dysplasia was detected in G2. These highgrade dysplastic changes in $\mathrm{G} 2$ with marked nuclear atypia extending to the superficial epithelium are shown in Figure 2B. The nuclei were hyperchromatic, enlarged, and rounded, often with irregular nuclear contours. Also, loss of nuclear polarity, often with nuclear stratification, was noticeable in G2.

Follicle reserve was significantly lower in $\mathrm{G} 2$ than in other groups ( $<<0.02, \mathrm{MWU}$ test). However, considering the treatment groups, follicle reserve was more similar to G1 in G4 ( $p<0.02$, Mann Whitney $\mathrm{U}$ test).

\section{Discussion}

In the current study, autologous ovarian transplantation by itself increased dysplastic changes in the ovarian surface epithelium in rats. It was observed that the use of Vit $\mathrm{C}$ significantly reduced these dysplastic changes. While serum and tissue MDA levels were significantly higher in the transplant-only group, a significant decrease was observed in the erythrocyte SOD level compared to the other groups. High SOD and low serum and tissue MDA levels in the Vit $\mathrm{C}$ group were both significantly different than those seen in the Vit $\mathrm{E}$ group. Therefore, it was determined that the use of Vit $\mathrm{C}$ was more effective than the use of Vit $\mathrm{E}$ for antioxidative protection during ovarian transplantation in rats.

According to the literature review conducted on Pub-Med (ovarian transplantation, ovarian surface epithelial dysplasia, ovarian follicle reserve, Vit E, Vit C), the current study is the first to be conducted on this specific subject.

Previous studies have been conducted on transplantation models using different substances, such as antioxidant agents or angiogenic factors. However, inflammation, oxidative stress, and apoptosis are all integral mechanisms that are involved in organ damage in organs susceptible to ischaemic reperfusion $(I / R)$, such as transplanted ovaries. Therefore, this study hypothesised that the IP injection of either Vit $E$ or Vit $\mathrm{C}$ prior to transplantation would protect the ovarian follicle reserve and surface epithelium from damage due to oxidative stress and consequently reduce the likelihood of postoperative complications.

Previous studies have shown that the transplanted ovaries suffer ischaemia and potential follicular atresia during and after tissue revascularisation, regardless of the transplant location (16). The mechanism of ischaemia causes energy depletion and oxidative stress, which in turn leads to the damage of lipids, DNA, enzymes, and structural proteins, which consequently results in cell death (17). In addition, transplanted tissues have been shown to have heightened sensitivity to hypoxia and undergo displacement of neutrophils and macrophages, causing tissue destruction and fibrosis (18).

Most ovarian cancers are thought to arise from surface epithelial cells that are disrupted during ovulation (19). During the follicular mechanics of ovulation, inflammatory mediators and reactive oxidant species are produced in the ovaries (20). In the current study, harmful cellular changes due to hypoxia in the 
ovarian surface epithelium and follicle reserve were histopathologically observed. The effect of this oxidative stress on normal cells was found to be consistent with the existing literature (21). Ovarian transplantation significantly increased ovarian surface epithelial stratification, tufting, chromatin irregularity, nucleus contour irregularity, nucleus size, nuclear-cytoplasmic ratio, pleomorphism, and hyperchromasia in rats. In rats that underwent ovarian transplantation without Vit $\mathrm{E}$ and Vit $\mathrm{C}$ treatment, a significant increase was seen in all parameters relating to the ovarian surface epithelium except in nuclear contour irregularity, nucleoli presence, nuclear-cytoplasmic ratio, mitosis, and chromatin irregularity. Vit $\mathrm{C}$ was found to be effective at protecting the ovarian surface epithelium from dysplastic changes. Therefore, using Vit $\mathrm{C}$ before ovarian transplantation can prevent the harmful effects of the inevitable I/R damage that occurs during ovarian transplantation. The insufficient protective effect of Vit $E$ could be explained by the short exposure time or the use of a fatty form of Vit $E$, which may have resulted in inadequate exposure to the transplanted ovaries. Therefore, the differences in Vit $\mathrm{E}$ findings can be attributed to the methodological differences between studies, including the route of administration, the duration of exposure to Vit $\mathrm{E}$ after transplantation, or the transplantation site of ovarian tissue (22).

Ovarian follicle reserve was found to be significantly lower in the transplantation model group compared to the other groups, although a decrease was still seen in the groups that received Vit C and Vit $\mathrm{E}$. One possible explanation for this finding is that the concentration of the single doses of Vit $\mathrm{E}$ and Vit $\mathrm{C}$ used in the current study may not have been sufficient to remove free radicals generated by prolonged ischaemia. Although the concentration of Vit $C$ used appears to be effective at protecting follicle cultures, it is unknown whether this concentration is optimal in tissue (23). Therefore, future studies could investigate the clinical efficacy and relevance of using Vit $C$ and Vit $E$ to protect ovarian tissue from ischaemia after transplantation. Although it was observed that more follicles were lost during ischaemia when there was no antioxidant treatment, even with antioxidant treatments, over $50 \%$ of follicles were still lost due to ischemia. Therefore, the most critical issue for effective ovarian transplantation is to minimise ischaemia before and during angiogenesis. During the revascularisation of the transplanted tissue, hypoxia causes necrosis and subsequent follicular loss. Therefore, some degree of follicle loss during the procedure was inevitable in the current study.

In the existing literature, human vaccines have been transplanted into immunodeficient mice in order to elicit the effect of antioxidants. Abir observed a lack of antiapoptotic activity when grafts were incubated with Vit E before transplantation (24). In the current study, lower tissue and serum MDA levels in groups that received Vit $E$ suggests that Vit $E$ elicits more of an antioxidant effect on transplanted ovaries than Vit $C$. Tissue and serum MDA levels were higher in the transplantation model group. Vit $C$ treatment resulted in lower serum and tissue MDA concentrations compared to Vit $E$ treatment. This result is also correlated to the histopathological findings of Vit C, which showed that it prevented ischaemic damage during transplantation. According to Tavasoli, Vit $\mathrm{C}$ has physiological antioxidant properties to decrease I/R by reducing the expression of proinflammatory chemokines and lipid peroxidation. In addition, Tavasoli has shown that intravenous injection of Vit $\mathrm{C}$ has a protective effect on the intestinal mucosa (25). Another study showed that a single dose of Vit C immediately after bloodstream reperfusion 
significantly reduced I/R injuries in kidney tissue (26). According to Gunel, depending on the MDA levels, Vit $\mathrm{C}$ showed a more significant antioxidant effect in rabbits compared to Vit $\mathrm{E}$ regarding intestinal $\mathrm{I} / \mathrm{R}$ injury (27). This finding is consistent with the current study.

In fresh and frozen/thawed cortical sections of bovine ovaries, stromal cells are more prone to ischaemia than primordial follicles, and the administration of Vit $\mathrm{C}$ reduces apoptosis in the ovarian cortex (28). The results of the current study showed that Vit $C$ reduced tissue and serum MDA levels compared to the transplantation-only group, which is consistent with the existing literature. However, while Vit $\mathrm{C}$ and Vit $\mathrm{E}$ have significant beneficial effects on post-transplantation ovarian tissue, there are still marked differences compared to normal ovarian tissue. Furthermore, the control group had the lowest concentrations of both tissue and serum MDA, suggesting that further research is needed to determine how to control the oxidative stress mechanism.

SOD is an enzyme and antioxidant system marker that catalyses the superoxide (02-) radical to ordinary molecular oxygen (02) and hydrogen peroxide ( $\mathrm{H} 2 \mathrm{O} 2)$. $\mathrm{H} 2 \mathrm{O} 2$ is produced as a by-product of oxygen metabolism and, if not regulated, causes multiple types of cell damage (29). Therefore, it is an important target for antioxidant defence in all living cells. Although the use of Vit $E$ and Vit $C$ increased SOD levels when compared to the transplantation-only group, the highest erythrocyte SOD level was seen in the control group. This indicates that the concentrations used of Vit $\mathrm{C}$ and Vit $\mathrm{E}$ do not affect the oxidative stress mechanism as much as the normal tissue levels of both. Normal tissue level can be achieved by increasing the applied doses of Vit $\mathrm{E}$ or Vit $\mathrm{C}$ or by applying them together. Overall, it was found that antioxidant use is beneficial for reducing the damages caused during ovarian transplantation. These findings are consistent with the results of Tavasoli et al. (25). However, further research is needed to examine the molecular mechanism of administering a single Vit $\mathrm{C}$ and Vit $\mathrm{E}$ dose in autologous ovarian transplantation in rats.

Although the current study has promising results, it has some limitations. Since this is an animal study, the results may not be adopted directly and linearly to human beings. Additional studies should be conducted on this topic.

Using Vit $\mathrm{E}$ and Vit $\mathrm{C}$ in autologous ovarian transplantation in rats reduces the dysplastic changes of the ovarian surface epithelium and preserves the follicle reserve in the ovaries. While the use of Vit $\mathrm{C}$ and Vit E decreases tissue MDA and serum MDA levels, they increase erythrocyte SOD levels. Overall, Vit C was more effective in protecting against oxidative stress than Vit $\mathrm{E}$.

\section{Declarations}

\section{CONFLICTS OF INTEREST}

The authors declare that there are no conflicts of interest.

\section{DATA AVAILABILITY}


Our data is available, if requested.

\section{AUTHOR CONTRIBUTIONS STATEMENT}

T.S., K.S. and O.I. wrote the main manuscript text and E.K., H.P., K.S., and M.T. collected data. All authors reviewed the manuscript.

\section{References}

1. Anderson RA, Mitchell RT, Kelsey TW, Spears N, Telfer EE, Wallace WH. Cancer treatment and gonadal function: experimental and established strategies for fertility preservation in children and young adults. Lancet Diabetes Endocrinol. 2015 Jul;3(7):556-67.

2. Practice Committee of American Society for Reproductive Medicine. Ovarian tissue cryopreservation: a committee opinion. Fertil Steril. 2014 May;101(5):1237-43.

3. Havrilesky LJ, Moorman PG, Lowery WJ, Gierisch JM, Coeytaux RR, Urrutia RP, Dinan M, McBroom AJ, Hasselblad V, Sanders GD, Myers ER. Oral contraceptive pills as primary prevention for ovarian cancer: a systematic review and meta-analysis. Obstet Gynecol. 2013 Jul;122(1):139-147.

4. Soares ROS, Losada DM, Jordani MC, Évora P, Castro-E-Silva O. Ischemia/Reperfusion Injury Revisited: An Overview of the Latest Pharmacological Strategies. Int J Mol Sci. 2019 Oct 11;20(20):5034.

5. Salama M, Woodruff TK. New advances in ovarian autotransplantation to restore fertility in cancer patients. Cancer Metastasis Rev. 2015 Dec;34(4):807-822.

6. Campbell BK, Hernandez-Medrano J, Onions V, Pincott-Allen C, Aljaser F, Fisher J, McNeilly AS, Webb $\mathrm{R}$, Picton HM. Restoration of ovarian function and natural fertility following the cryopreservation and autotransplantation of whole adult sheep ovaries. Hum Reprod. 2014 Aug;29(8):1749-63.

7. Murdoch WJ, Martinchick JF. Oxidative damage to DNA of ovarian surface epithelial cells affected by ovulation: carcinogenic implication and chemoprevention. Exp Biol Med (Maywood). 2004 Jun;229(6):546-52.

8. Halliwell B. Vitamin C and genomic stability. Mutat Res. 2001 Apr 18;475(1-2):29-35.

9. Azari O, Kheirandish R, Azizi S, Farajli Abbasi M, Ghahramani Gareh Chaman S, Bidi M. Protective Effects of Hydrocortisone, Vitamin $\mathrm{C}$ and $\mathrm{E}$ Alone or in Combination against Renal IschemiaReperfusion Injury in Rat. Iran J Pathol. 2015 Fall;10(4):272-80.

10. Ohkawa H, Ohishi N, Yagi K. Assay for lipid peroxides in animal tissues by thiobarbituric acid reaction. Anal Biochem. 1979 Jun;95(2):351-8.

11. Satoh K. Serum lipid peroxide in cerebrovascular disorders determined by a new colorimetric method. Clin Chim Acta. 1978 Nov 15;90(1):37-43.

12. Yagi K. Assay for blood plasma or serum. Methods Enzymol. 1984;105:328-31.

13. Fairbanks VF, Klee GG. Biochemical aspect of hematology. In: Burtis CA, Ashwood ER, eds. Tietz Textbook of Clinical Chemistry, 3rd 
14. Souza AZ, Fonseca AM, Izzo VM, Clauzet RM, Salvatore CA. Ovarian histology and function after total abdominal hysterectomy. Obstet Gynecol. 1986 Dec;68(6):847-9.

15. Sapmaz E, Akpolat N. Examination of The Effect of Trichloroacetic Acid Attachment and Instillation Methods on Ovarian Reserve and Dysplasic Changes in Ovarian Surface Epithelium. Fırat Tıp Dergisi 2012; 17(2): 71-75.

16. Wang Y, Chang Q, Sun J, Dang L, Ma W, Hei C, Shen X, Zhao C, Cai Y, Pei X, Zhang X, Wang Y, Jiang X. Effects of HMG on revascularization and follicular survival in heterotopic autotransplants of mouse ovarian tissue. Reprod Biomed Online. 2012 Jun;24(6):646-53.

17. Kim JS, Qian T, Lemasters JJ. Mitochondrial permeability transition in the switch from necrotic to apoptotic cell death in ischemic rat hepatocytes. Gastroenterology. 2003 Feb;124(2):494-503.

18. Vollmar B, Glasz J, Menger MD, Messmer K. Leukocytes contribute to hepatic ischemia/reperfusion injury via intercellular adhesion molecule-1-mediated venular adherence. Surgery. 1995 Feb;117(2):195-200.

19. Murdoch WJ, Townsend RS, McDonnel AC. Ovulation-induced DNA damage in ovarian surface epithelial cells of ewes: prospective regulatory mechanisms of repair/survival and apoptosis. Biol Reprod. 2001 Nov;65(5):1417-24.

20. Kodaman PH, Behrman HR. Endocrine-regulated and protein kinase C-dependent generation of superoxide by rat preovulatory follicles. Endocrinology. 2001 Feb;142(2):687-93.

21. Pizzino G, Irrera N, Cucinotta M, Pallio G, Mannino F, Arcoraci V, Squadrito F, Altavilla D, Bitto A. Oxidative Stress: Harms and Benefits for Human Health. Oxid Med Cell Longev. 2017;2017:8416763.

22. Nugent $D$, Newton $H$, Gallivan L, Gosden RG. Protective effect of vitamin E on ischaemia-reperfusion injury in ovarian grafts. J Reprod Fertil. 1998 Nov;114(2):341-6.

23. Thomas FH, Leask R, Srsen V, Riley SC, Spears N, Telfer EE. Effect of ascorbic acid on health and morphology of bovine preantral follicles during long-term culture. Reproduction. 2001 Sep;122(3):487-95.

24. Abir R, Fisch B, Jessel S, Felz C, Ben-Haroush A, Orvieto R. Improving posttransplantation survival of human ovarian tissue by treating the host and graft. Fertil Steril. 2011 Mar 15;95(4):1205-10.

25. Tavasoli Mehdi, et al. evaluation of combination therapy with hydrocortisone, vitamin $C$, and vitamin $E$ in a rat model of intestine ischemia-reperfusion injury. Comparative Clinical Pathology 2018; 27(2): 433-439.

26. Azari O, Kheirandish R, Azizi S, Farajli Abbasi M, Ghahramani Gareh Chaman S, Bidi M. Protective Effects of Hydrocortisone, Vitamin $\mathrm{C}$ and $\mathrm{E}$ Alone or in Combination against Renal IschemiaReperfusion Injury in Rat. Iran J Pathol. 2015 Fall;10(4):272-80.

27. Günel E, Cağlayan F, Cağlayan O, Dilsiz A, Duman S, Aktan M. Treatment of intestinal reperfusion injury using antioxidative agents. J Pediatr Surg. 1998 Oct;33(10):1536-9.

28. Kim SS, Yang HW, Kang HG, Lee HH, Lee HC, Ko DS, Gosden RG. Quantitative assessment of ischemic tissue damage in ovarian cortical tissue with or without antioxidant (ascorbic acid) treatment. Fertil Steril. 2004 Sep;82(3):679-85. 
29. Hayyan M, Hashim MA, AINashef IM. Superoxide Ion: Generation and Chemical Implications. Chem Rev. 2016 Mar 9;116(5):3029-85.

\section{Tables}

Table 1: Median values of dysplastic change parameters of the ovarian surface epithelium in the control and experimental groups. Values are presented as mean \pm SD. NS $=p>0.02, *=p<0.02$, Mann Whitney U Test.

\begin{tabular}{|llllll|}
\hline Dysplastic Change Parameter & $\mathrm{G} 1$ & $\mathrm{G} 2$ & $\mathrm{G} 3$ & $\mathrm{G} 4$ & P-value \\
\hline Stratification & $0 \pm 0$ & $0.5 \pm 0.1$ & $0 \pm 0$ & $0 \pm 0$ & $*$ \\
\hline Tufting & $0.1 \pm 0.3$ & $0.2 \pm 0.1$ & $0 \pm 0$ & $0 \pm 0$ & $*$ \\
\hline Chromatin irregularity & $0 \pm 0$ & $0 \pm 0$ & $0 \pm 0$ & $0 \pm 0$ & $\mathrm{NS}$ \\
\hline Nuclear contour irregularity & $0 \pm 0$ & $0.2 \pm 0.1$ & $1.0 \pm 0.5$ & $0.4 \pm 0.2$ & $\mathrm{NS}$ \\
\hline Increase in nucleus/cytoplasm ratio & $0 \pm 0$ & $0.1 \pm 0.1$ & $1.0 \pm 0.3$ & $0.3 \pm 0.2$ & $\mathrm{NS}$ \\
\hline Nucleolus presence of epithelial cells & $0 \pm 0$ & $0 \pm 0$ & $0 \pm 0$ & $0 \pm 0$ & NS \\
\hline Mitosis & $0 \pm 0$ & $0 \pm 0$ & $0 \pm 0$ & $\mathrm{NS}$ & $\mathrm{NS}$ \\
\hline Hyperchromasia & $0 \pm 0$ & $0.8 \pm 0.1$ & $0 \pm 0$ & $0.3 \pm 0.1$ & $*$ \\
\hline Pleomorphism & $0 \pm 0$ & $0.5 \pm 0$ & $0 \pm 0$ & $0.1 \pm 0$ & $*$ \\
\hline Total & $0.1 \pm 0.3$ & $2.3 \pm 0.5$ & $2.0 \pm 0.8$ & $1.1 \pm 0.5$ & \\
\hline
\end{tabular}

Table 2: Changes in the ovarian surface epithelium, follicle reserve, tissue MDA, serum MDA, and erythrocyte SOD in all groups. Values are presented as mean \pm SD. Superscript letters indicate a significant difference between the means within the same parameter $(p<0.02$, MWU test with Bonferroni correction). The means are in descending order $(a>b>c>d)$.

\begin{tabular}{|lllll|}
\hline Parameter & G1 & G2 & G3 & G4 \\
\hline Ovarian Follicle Reserve (number) & $50 \pm 0,3^{\mathrm{a}}$ & $5 \pm 0,5^{\mathrm{d}}$ & $15 \pm 0,8^{\mathrm{c}}$ & $24 \pm 0,4^{\mathrm{b}}$ \\
\hline Ovary Surface Epithelium (p) & $0.28 \pm 0.48^{\mathrm{c}}$ & $2.3 \pm 0.75^{\mathrm{a}}$ & $2.0 \pm 0.8^{\mathrm{a}}$ & $1.1 \pm 0.5^{\mathrm{b}}$ \\
\hline Tissue MDA (nmol/g) & $3.6 \pm 0.3^{\mathrm{c}}$ & $8.7 \pm 0.04^{\mathrm{a}}$ & $4.3 \pm 0.17^{\mathrm{b}}$ & $4.17 \pm 0.17^{\mathrm{d}}$ \\
\hline Serum MDA (nmol/ ml) & $0.5 \pm 0.01^{\mathrm{d}}$ & $1.7 \pm 0.1^{\mathrm{a}}$ & $1.2 \pm 0.06^{\mathrm{b}}$ & $1.02 \pm 0.01^{\mathrm{c}}$ \\
\hline Erythrocyte SOD $(\mathrm{U} / \mathrm{g} \mathrm{Hb})$ & $0.24 \pm 0.02^{\mathrm{a}}$ & $0.075 \pm 0.08^{\mathrm{d}}$ & $0.16 \pm 0.01^{\mathrm{c}}$ & $0.2 \pm 0.02^{\mathrm{b}}$ \\
\hline
\end{tabular}




\section{Figures}

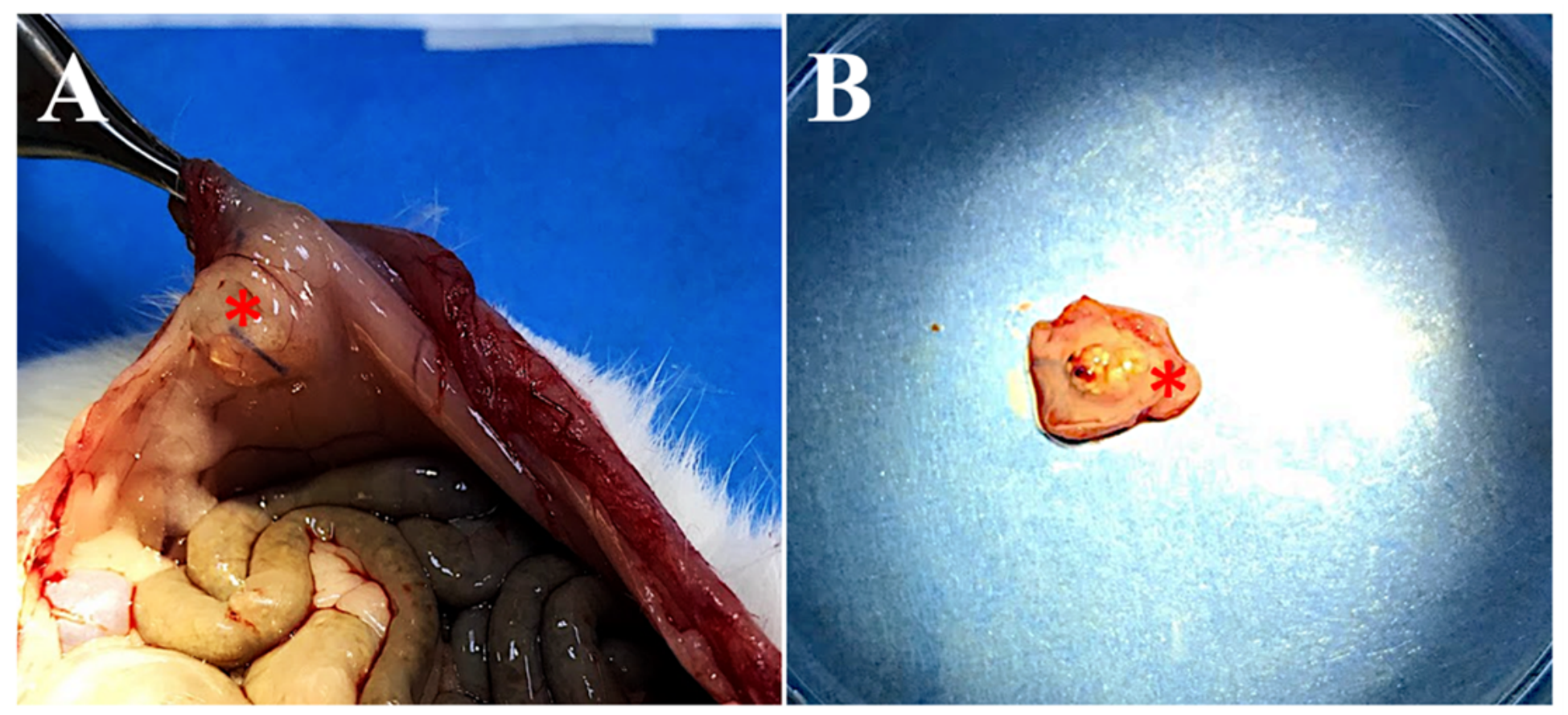

\section{Figure 1}

Revascularisation was macroscopically observed in ovarian tissue after transplantation in G2, G3, and G4 (A). Image of the transplanted ovary sutured to the vascular plexus of the peritoneal wall after extirpation (B). The transplanted ovarian tissue is visible $\left(^{\star}\right)$.

G1

G2

G3

G4
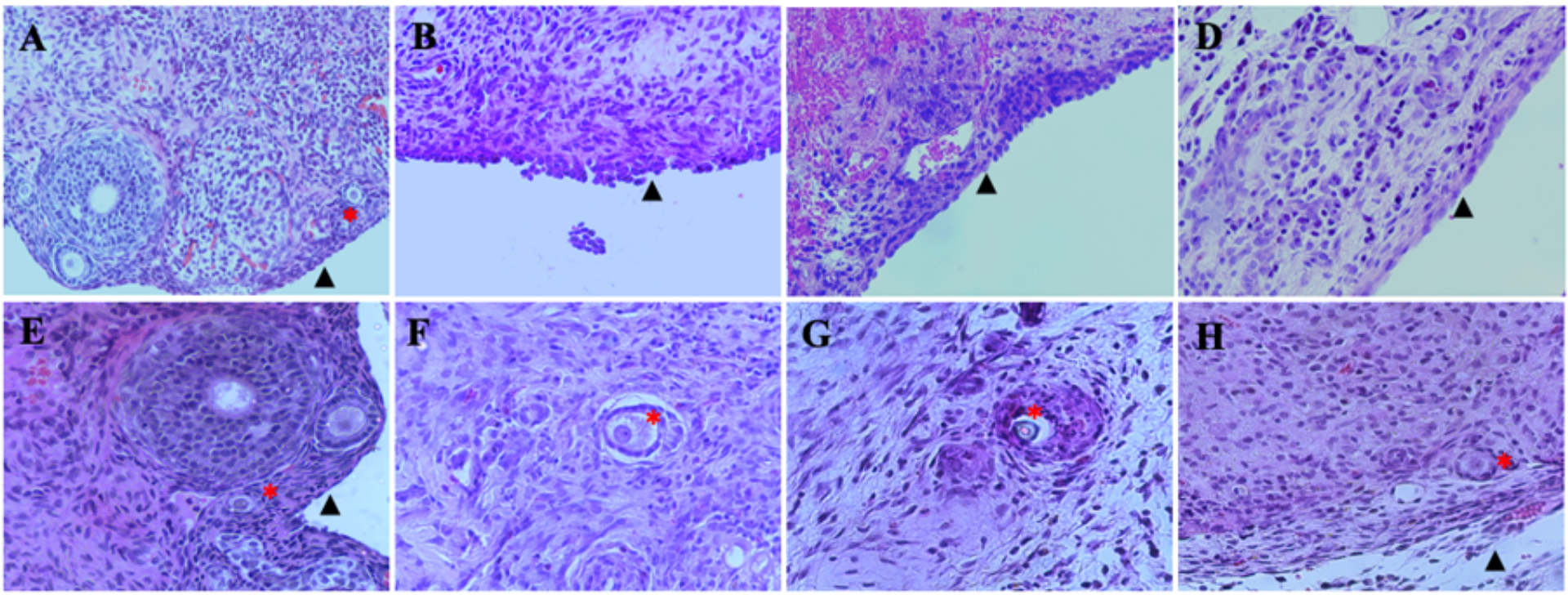

Figure 2 
Histopathological examination of all groups. G1: control, G2: transplantation, G3: Vit E + transplantation, G4: Vit C + transplantation. Arrows: ovarian surface epithelia. Asterisk: primordial follicles. Light microscopy. A-D: HEX200, E-H: HEX400. 